\title{
The importance of precautionary motives in explaining individual and aggregate saving* A comment
}

\author{
Miles S. Kimball \\ University of Michigan, Department of Economics, Ann Arbor, Michigan 48109
}

Glenn Hubbard, Jonathan Skinner, and Stephen Zeldes take up the difficult but important task of doing a realistic life-cycle model of saving that incorporates the effects of uncertainty and of uncertainty in interaction with social insurance. They have a maintained assumption that private income insurance is not available and that health insurance is incomplete. This puts the model in more or less the same "world" as the models of Barsky, Mankiw, and Zeldes (1986), Zeldes (1989), and Kimball (1990). The assumption of incomplete income or medical insurance seems on solid ground to me. ${ }^{1}$

There are four things going on in this model: the effects of (1) lifespan risk, (2) medical expense risk, (3) labor income risk, and (4) means-tested social insurance. Let me address each in turn.

Lifespan risk. From Hubbard, Skinner, and Zeldes' tables, it is apparent that lifespan risk is not doing very much, given the particular parameters they choose. An illustrative calculation suggests why they are getting so little action from lifespan risk.

In Blanchard's (1985) overlapping generations model with a constant death rate $\delta$, when the real interest rate is constant at $r$, the (marginal and)

\footnotetext{
${ }^{1}$ If there is incomplete insurance, and the extent of the insurance does not change in reaction to the interventions under consideration, the exact reason for the incomplete insurance need not be explicitly modeled. (For example, the fixed costs of introducing a new type of insurance might make it unprofitable, so that the amount of that type of insurance is zero and likely to stay at zero in the face of the intervention at issue. The results would then be the same as if one had assumed that the quantity of that type of insurance was exogenously set at zero.) Since Hubbard, Skinner, and Zeldes do not consider any interventions but are trying to explain the existing average level of saving, it is not necessary for them to explicitly model the reason for incomplete insurance.
} 
average propensity to consume out of wealth is $s(\rho+\delta)+(1-s) r$, where $s$ is the elasticity of intertemporal substitution and $\rho$ is the utility discount rate. If $\rho=r$, as it will be in a static steady state of the economy, the average propensity to consume out of wealth becomes $r+s \delta$.

For comparison, when death is certain after exactly $T=\frac{1}{\delta}$ years (the mean remaining lifespan in Blanchard's model), the average propensity to consume when $r=\rho$ is:

$$
\frac{r}{1-e^{-r T}}=\frac{r}{1-e^{-r / \delta}} .
$$

The question of greatest interest here-When does lifespan risk lower current consumption?-reduces (at time zero for this simple example) to the question of "When is

$$
r+s \delta \leq \frac{r}{1-e^{-r / \delta}} ? "
$$

Clearly, since the right-hand-side is greater than $r$ and the death rate $\delta$ is positive, varying the elasticity of intertemporal substitution $s$ can make inequality (1) go either way. When $s$ is small, lifespan risk lowers current consumption; when $s$ is large, lifespan risk raises current consumption.

What about the particular parameters used by Hubbard, Skinner, and Zeldes? With $\rho=r=.03 / y r, s=\frac{1}{\gamma}=\frac{1}{3}$, and for mean lifespan something like $T=66 \frac{2}{3}$ yrs (so that $\delta=\frac{1}{T}=.015 / \mathrm{yr}$ ),

$$
r+s \delta=.035 / y r>.0347 / y r \approx \frac{r}{e^{-r / \delta}} .
$$

In words, for these parameters and this example, lifespan risk raises the average propensity to consume at time zero, but only slightly.

Despite the additional complications in Hubbard, Skinner, and Zeldes' model, this simple example may help to illuminate why, given the parameters they use, lifespan risk has so little effect on consumption or saving in their model.

Medical expense risk. From Hubbard, Skinner, and Zeldes' tables, uncertainty about medical expenses also seems to have little effect on saving. The basic reason is that the medical expense risks they model are small in relation to lifetime resources.

Consider the following illustrative calculation, using numbers close to those used by Hubbard, Skinner, and Zeldes. Starting from a mean out-ofpocket medical expenditure of $\$ 1,000$, a standard deviation of $.4 / \sqrt{y r}$ and AR( 1 ) coefficient of .9 suggests a typical shock of $\$ 400$ lasting for more or less ten years. Given some discounting of future expenditures by the real interest rate, the capitalized value of a typical shock is thus less than $\$ 4,000$. This is bound to be quite small in relation to lifetime resources (human wealth + nonhuman wealth). 
For comparison, an income shock one annual standard deviation (.15 of the mean income $\$ 30,000$ ) that decays according to the AR(1) coefficient .95 has, at a real interest rate of $.03 / \mathrm{yr}$, a capitalized value of;

$$
.15(\$ 30,000) /(.05+.03)=\$ 56,250,
$$

which could be a substantial fraction of lifetime resources. ${ }^{2}$

The difference between a typical out-of-pocket medical expenditure shock worth less than $\$ 4,000$ in capitalized value and a labor income shock worth over $\$ 55,000$ in capitalized value is heightened by the fact that it is the variance of innovations to lifetime resources that is most closely related to the magnitude of precautionary saving effects, rather than the standard deviation of innovations to lifetime resources. As a consequence, squaring the capitalized value of a typical shock gives the best simple indicator of the likcly size of precautionary saving cffects from a given type of risk. Based on this simple indicator, the precautionary saving effects induced by income risk in this model should be on the order of a hundred times larger than the precautionary saving effects induced by medical expenditure risk.

Labor income risk. Precautionary saving due to labor income risk does play an important role in Hubbard, Skinner, and Zeldes' model. Kimball (1992) gives a simple treatment of the theory of precautionary saving due to labor income risk. The strength of the precautionary saving motive in this context depends on the curvature of the function for the marginal utility of saving (which is closely related to the marginal utility of future consumption). Kimball and Weil (1992) work out the formula for the strength of the precautionary saving motive in the general case of Kreps-Porteus preferences that do not force the elasticity of intertemporal substitution to be equal to relative risk tolerance (the reciprocal of relative risk aversion). For KrepsPorteus preferences, the local measure of the strength of the precautionary saving motive $(P)$ is given by;

$$
P=\gamma(1+s \epsilon),
$$

where $\gamma$ is relative risk aversion, $s$ is the (separate) elasticity of intertemporal substitution, and $\epsilon$ is the wealth elasticity of absolute risk tolerance (which is approximately equal to the wealth elasticity of risky investment).

The wealth elasticity of absolute risk tolerance $\epsilon$ is equal to 1 for constant relative risk aversion utility and is positive for any utility function with decreasing absolute risk aversion. Thus, the formula (2) implies-among other

\footnotetext{
${ }^{2}$ It should be apparent that the capitalized value of an income or medical expenditure shock is very sensitive to how persistent it is. In the absence of liquidity constraints, only persistent shocks are likely to engender much precautionary saving. Transient shocks to resources should have little effect on saving-or, in general equilibrium, little effect on either saving or the real interest rate-as has been documented iny Heaton and Lucas (1994).
} 
things-that even under this general preference structure, whenever absolute risk aversion is decreasing, the precautionary saving motive is stronger than risk aversion. In other words, as long as absolute risk aversion is decreasinga safe assumption, since it is a necessary condition for the wealth elasticity of risky investment to be uniformly positive - precautionary saving effects must be big if the effects of risk aversion are.

The operational meaning of the statement "If absolute risk aversion is decreasing, then the precautionary saving motive is stronger than risk aversion" is this: if absolute risk aversion is decrcasing, then cven a risk that the agent is indifferent to (because it is compensated by a positive mean) tends to lead to increased saving. ${ }^{3}$ Thus, (given decreasing absolute risk aversion) a risk, when fully compensated by its positive mean as far as risk aversion is concerned, is still not fully compensated as far as the precautionary saving motive is conccrned.

The logic behind this statement is set out in Kimball (1992) and Kimball and Weil (1992). This logic is quite widely applicable, even to preference structures more general than Kreps-Porteus preferences. Whatever else it means in a particular model, decreasing absolute risk aversion should mean that having accumulated more wealth by a particular time should make an agent more willing to take risks of a given absolute size that are compensated by having a positive mean. ${ }^{4}$ Therefore, decreasing absolute risk aversion means that saving (which leads to a greater accumulation of wealth) and compensated risk-taking are complements. But complementarity goes both ways. If finding a box of ketchup on one's doorstep would make one more eager to get hot dogs, finding a box of frozen hot dogs on one's doorstep must make one more eager to get some ketchup. More to the point, if additional saving would make an agent eager to take a compensated risk that she or he was previously indifferent to, then facing a compensated risk to which an agent is indifferent must make her or him more eager to do additional saving that she or he was previously indifferent to. Thus, an indifferent risk that is compensated enough to counteract risk aversion is not compensated enough to counteract the precautionary saving motive.

Applying formula (2) to Hubbard, Skinner, and Zeldes' work, with $\gamma=$ $3, s=\frac{1}{\gamma}=.333$ and $\epsilon=1$, the strength of the precautionary saving motive in their simulations is 4 , in units that are fully comparable to the units one uses in saying that relative risk aversion in their simulations is 3. By varying $\gamma$ - or to a lesser extent, by varying $s$ or $\epsilon$-it is easy to obtain precautionary

\footnotetext{
${ }^{3}$ Stated this way, the result is due originally to Drèze and Modigliani (1972).

${ }^{4}$ The one important exception I can think of is that when the usual principle that bygones are bygones fails badly enough, the lower past consumption entailed by the additional saving might somehow tend to lower an agent's willingness to take risks now despite the greater level of accumulated wealth now
} 
saving effects due to labor income risk that are much larger or much smaller than the ones Hubbard, Skinner, and Zeldes find. 'The parameters Hubbard, Skinner, and Zeldes choose do not seem to me unreasonable, but the uncertainty about the true magnitude of these parameters is still great, as is the corresponding uncertainty about the true magnitude of precautionary saving effects. ${ }^{5}$

Means-tested social insurance. Means-tested social insurance also has a big effect on the amount of saving predicted in Hubbard, Skinner, and Zeldes' model. Hubbard, Skinner, and Zeldes (1992) have a graph that illustrates why. In essence, the existence of a socially-provided consumption floor causes the marginal utility of saving to drop suddenly to zero below the level of saving that would barely finance the floor level of consumption without help. As a consequence, agents with low wealth save nothing in the presence of means-tested social insurance. ${ }^{6}$ In the aggregate, this results in substantially lower saving.

The negative effect of social insurance on saving allows Hubbard, Skinner, and Zeldes to get roughly the same empirically plausible aggregate (wealth/labor income) ratio as Carroll (1992), even though Carroll assumes a weaker precautionary saving motive (relative prudence of 3 instead of 4) and less patience (a utility discount rate of $10 \% / \mathrm{yr}$ instead of $3 \% / \mathrm{yr}$ ).

\section{Concluding discussion}

There are several interesting dircetions in which to pursuc the kind of analysis done here in future work. Let me mention three. First, allowing an interaction between individual uncertainty and macroeconomic uncertainty might enable the model to make interesting predictions about the time-series behavior of aggregate consumption. Second, modest extensions of the model could be used to examine cohort cffects likc the effect on aggregate consumption of the large size of the baby-boom generation. Third, as Hubbard, Skinner, and Zeldes note, the model can be used directly to calculate the welfare effects of various alterations in the rules for social insurance.

\footnotetext{
${ }^{5}$ If the additional complexity of dealing with Kreps-Porteus preferences were not an issue, I would choose $\gamma=2.5$ and $s=.15$ based on my reading of the evidence. This would make the strength of the precautionary saving motive equal to 2.875 .

${ }^{6}$ As one looks at agents with higher and higher wealth, there will be a sudden jump from zero saving to a level of saving well above the level of saving that would barely finance the floor level of consumption without help. Saving barely the amount that would finance the consumption floor never makes sense, since it has a cost in reduced consumption now but no benefit in additional consumption later.
} 


\section{References}

Barsky, R.B., Mankiw. N.G.. and Zeldes, S.P., (1986). Ricardian Consumers with Keynesian Propensities. American Economic Review, 76: 676-691.

Blanchard, O.J., (1985). Debt, Deficits, and Fininte Horizons. Journal of Political Economy, 93: 223-247.

Carroll, C., (1992). The Buffer Stock Theory of Saving: Some Macroeconomic Evidence, Broolings Papers on Economic Activity. 2: 61-135.

Drèze, J.H. and Modigliani. F., (1972). Consumption Decisions under Uncertainty, Journal of Economic Theory, 5: 308-335.

Heaton, J. and Lucas. D.. (1994). Evaluating the Effects of Incomplete Mar kets on Risk Sharing and Asset Pricing. mimeo.

Hubbard. R.G.. Skinner. J.. Zeldes, S.P.. (1992). Precautionary Saving and Social Insurance, mimeo.

Kimball, M.S.. (1990). Precautionary Saving and the Marginal Propensity to Consume, NBER Worling Paper \#3403.

Kimball, M.S., (1992). Precautionary Motives for Holding Assets. The New Palgrave Dictionary of Money and Finance. Peter Newman. Murray Milgate. and John Eatwell (eds.). 3: 158-161. Stockton Press, New York. (NBER Working Paper \#358(6).

Kimball, M.S. and Vieil. P.. (1992). Precautionary Saring and Consumption Smoothing over Time and Possibilities. NBER Working Paper \#3976.

Zeldes. S.P., (1989). Optimal Consumption with Stochastic Income: Deviations from Certainty Equivalence. Quarterly Journal of Economics. 104: 275-298. 